\title{
The association between vascular factors and subjective memory impairment in older people: The HUNT Study, Norway
}

\author{
Ellen Melbye Langballe ${ }^{1}$, Kristian Tambs ${ }^{2}$, Ingvild Saltvedt ${ }^{3,4}$, Kristian Midthjell ${ }^{5}$ \\ and Jostein Holmen ${ }^{5}$ \\ 1) Department of Psychosomatics and Health Behaviour, Division of Mental Health, \\ Norwegian Institute of Public Health, Oslo, Norway \\ 2) Division of Mental Health, Norwegian Institute of Public Health, Oslo, Norway \\ 3) Department of Geriatrics, St. Olav Hospital, University Hospital of Trondheim, Norway \\ 4) Department of Neuroscience, Norwegian University of Science and Technology (NTNU), Trondheim, Norway \\ 5) HUNT Research Centre, Department of Public Health and General Practice, Faculty of Medicine, \\ Norwegian University of Science and Technology (NTNU), Trondheim, Norway \\ Correspondence: Ellen Melbye Langballe, Department of Psychosomatics and Health Behaviour, Division of Mental Health, \\ Norwegian Institute of Public Health, Oslo, Norway \\ E-mail: ellen.melbye.langballe@fhi.no Telephone: +47 21078376
}

\begin{abstract}
Objectives: Subjective memory impairment (SMI) is often considered an early sign of dementia. This study investigates the relationship between SMI and dementia-related vascular factors in older people.

Method: This study was based on data from 12,255 individuals, 65 years and older, participating in the Nord-Trøndelag health study, third survey 2006-08 (HUNT3). SMI, vascular diseases, exercise, smoking, and alcohol consumption were self-reported. Blood pressure, cholesterol and body mass index (BMI) were clinically measured. SMI were predicted using linear regression analysis.

Results: Stroke and heart disease were associated with SMI. High exercise intensity was associated with less SMI. Respondents with high systolic blood pressure (SBP) reported less SMI than those with moderate SBP. In men, low SBP was associated with significantly more SMI compared to those with moderate SBP. In women, moderate alcohol consumption compared to low alcohol consumption was associated with significantly more SMI.

Conclusion: SMI was positively associated with stroke and heart disease in this study. For the other investigated vascular factors, we did not find strong relationships with SMI. However, for preventive and treatment purposes, it is noteworthy that high exercise intensity and high systolic blood pressure was associated with less SMI in both genders.
\end{abstract}

\section{INTRODUCTION}

The mechanisms involved in subjective memory impairment (SMI) are complex (1). Persons with no objective signs of dementia may complain about their memory, whereas individuals suffering from dementia may lack insight into serious cognitive problems. Several studies have found a stronger association between SMI and depression, anxiety $(2,3)$ and personality factors (4) than objective measures of cognitive performance (5). However, cognitive complaints may predict cognitive decline at an earlier stage than objective tests $(6,7)$. Far from everyone reporting memory problems will develop dementia later on (7), but memory complaints may indicate early signs of dementia $(5,8,9)$.

An extensive overview of the current knowledge of vascular contributions to cognitive impairment and dementia has recently been published. In the overview, the increasing support for the hypothesis that potentially shared pathophysiological mechanisms are involved is emphasised (10). Several vascular factors may lead to cognitive impairment (11-14) and dementia (12). Traditionally, Alzheimer's disease has been interpreted as a neurodegenerative disorder without a vascular origin, but recent evidence supports the hypothesis that vascular factors and disorders may be involved in the development of both vascular dementia and Alzheimer's disease (13). This indicates that an effective way to minimize the number of new dementia cases on a population level may be through interventions programmes aimed at modifying vascular risk factors (15). However, associations between vascular factors and dementia are mostly only moderately strong. The exact relationships between vascular risk factors and neuronal degeneration remain poorly understood (16).

For both preventive and treatment purposes, recent research has focused on the identification of clinical symptoms that may indicate an early (preclinical) stage of dementia illnesses (17), such as if memory problems in non-demented individuals are associated with dementia-related vascular factors (18-20). Results from these studies are less clear than the findings from 
studies on the association between vascular factors and the risk of different dementia diseases. To be able to identify dementia illness in progress at early stages it is of importance to learn more about the association between different vascular factors and potential early signs of dementia. Hence, the aim of this study was to investigate the association between SMI in older people without a diagnosed dementia and dementiarelated vascular factors such as vascular diseases, blood pressure, cholesterol, exercise intensity, body mass index (BMI), waist-hip (WH) ratio, smoking, and alcohol consumption.

\section{Methods}

\section{Participants}

Nord-Trøndelag County is situated in the middle of Norway and is characterized by a stable and homogeneous population that constitutes $3 \%$ of the Norwegian population. The Nord-Trøndelag Health Study (HUNT) is a large population-based health survey that has been conducted three times over 20 years. The present analyses are based on data on subjective memory impairment (SMI) and cardiovascular factors from HUNT3, collected during 2006-08. The total adult (20 years, and older) population, 93,210 people, were invited, and 50,839 participated (54\%). The nine SMI questions were included in a questionnaire distributed to the participating population of men and women 30 years of age and older. Our study utilizes data from people 65 years and older, 12,255 individuals. The participation rate on the SMI-questions was $86.7 \%(n=10,621)$. Mean age was 73.5 years and $54 \%$ were women.

\section{Measures}

The Metamemory Questionnaire (MMQ) originally developed for the NORA-study (21) was used to assess subjective memory impairment (SMI). The nine items included in MMQ represent one latent factor: general self-rated memory impairment (21). The study participants were asked to rate perceived changes in their memory capacity by answering the following two questions: "Do you have problems with your memory?" and "Has your memory changed since you were younger?" The response categories for both these questions were "no", "yes, some", and "yes, a lot". In addition there were seven items relating to specific memory tasks: "Do you have problems remembering...": "what happened a few minutes ago", "the names of other people", "dates", "to carry out planned activities", "what happened a few days ago". Response categories used for these seven items were "never", "sometimes", and "often".

We used SPSS missing value analysis (MVA), expectation maximization for imputation of missing values in respondents with valid data for at least five out of the nine SMI items. By using the described imputation criteria, in the $13.3 \%$ missing records in the age-group over 65 years, 977 were imputed. The remaining $5.3 \%$ were treated as missing data. SMI was analysed as a continuous variable (range 9-27) using the z-scores of the sum of the nine SMI items.

The participants underwent medical examinations (measurement of blood pressure, height, weight, waisthip ratio), had blood samples drawn, and they completed self-administered questionnaires, including questions about medical history and lifestyle.

Blood pressure was for most of the respondents measured automatically 3 times at one-minute intervals using a non-invasive blood pressure monitor based on oscillometry (Dinamap 845XT; Critikon, Tampa, Florida). In the 65 years and older age group, the third measurement was skipped in $13.2 \%$ of the cases. In $1 \%$ of the respondents blood pressure was only measured once. In cases where the third measurement was missing, the second measurement was used. To adjust for the small, but significant difference between the second and third measurement (about $1 \mathrm{~mm}$ ), the scores in the analyses based on the second measurement only were adjusted by subtracting a constant equal to the mean difference between measurement 2 and 3 for both systolic and diastolic blood pressure. A nonfasting venous blood sample was collected from each individual, and total serum cholesterol and highdensity lipoprotein (HDL) cholesterol were measured. All the measured vascular factors were measured on continuous scales. Prior to the regression analysis, blood pressure (SBP and DBP) and cholesterol (total and HDL) were re-coded into dummy variables to investigate the association between SMI and different levels of these variables. Categories were decided according to commonly used threshold values: SBP: $<120,120-159, \geq 160$; DBP: $<70,70-89, \geq 90$; total-C: $<5,5-6, \geq 7$; HDL-C: $<1,1-2, \geq 2$.

Based on the responses in the four questions about myocardial infarction, angina pectoris, heart failure or unspecified heart disease (response options: yes/no), heart disease was constructed into a dichotomous variable $(0=$ no heart disease, $1=$ angina pectoris, myocardial infarction, or other heart diseases). Missing values were treated as no heart disease.

Body mass index (BMI) was calculated dividing weight $(\mathrm{kg})$ by height $(\mathrm{cm})$ squared. Waist-hip ratio (WH-ratio) was calculated dividing the waist $(\mathrm{cm})$ by the hip measures $(\mathrm{cm})$ for each individual. Both BMI and WH-ratio was entered into the analyses as continuous scales.

Smoking was analysed as a dichotomised variable, "non-smoker" and "former/present smoker," based on the responses to five questions about former and present smoking, and independent of the age that former smokers reported to have stopped smoking." Alcohol consumption, i.e., frequencies and total units, were measured by two questions: "How often have you been drinking alcohol during the last 12 months?" (8 response categories: "4-7 times per week" - "never"), and "How many glasses of beer, wine or liquor do you usually drink in the course of two weeks?" (separate 
Table 1. Participants in the HUNT3 Study (2006-08) answering questions about subjective memory impairment (SMI). Descriptive statistics for women and men 65 years or older.

\begin{tabular}{|c|c|c|c|}
\hline & $\begin{array}{l}\text { WOMEN (N=6645) } \\
\text { Mean (SD) }\end{array}$ & $\begin{array}{l}\text { MEN }(\mathrm{N}=5610) \\
\text { Mean (SD) }\end{array}$ & $\mathrm{p}$ \\
\hline Age & $73.8(6.6)$ & $73.1(6.2)$ & $<.01 *$ \\
\hline Dichotomous self-reported data & Yes $(\%$ within sex $)$ & Yes $(\%$ within sex $)$ & \\
\hline Stroke & $364(5.5)$ & $414(7.4)$ & $<.01 * *$ \\
\hline $\begin{array}{l}\text { Heart disease (myocardial infarction, angina pectoris, } \\
\text { heart failure, or other heart disease unspecified) }\end{array}$ & $1180(17.8)$ & $1677(29.9)$ & $<.01 * *$ \\
\hline Smoking & $2698(44.0)$ & $3709(69.9)$ & $<.01 * *$ \\
\hline High BP ( $>140 / 90$ objectively measured) or BP medication & $3319(53.8)$ & $2789(53.8)$ & $.96^{* *}$ \\
\hline Self reported data, continuous scale & Mean (SD) & Mean (SD) & \\
\hline Alcohol *** & $7.5(7.51)$ & $4.5(4.89)$ & $<.01^{*}$ \\
\hline Exercise $* * *$ & $.98(.65)$ & $1.13(.76)$ & $<.01 *$ \\
\hline \multicolumn{4}{|l|}{ Measured data, continuous scale } \\
\hline BMI & $27.75(4.70)$ & $27.34(3.62)$ & $<.01^{*}$ \\
\hline BP diastolic & $72.25(11.68)$ & $76.67(11.11)$ & $<.01^{*}$ \\
\hline BP systolic & $142.12(21.24)$ & $140.78(19.85)$ & $<.01^{*}$ \\
\hline Triglycerides & $1.69(0.86)$ & $1.74(0.93)$ & $<.01 *$ \\
\hline HDL-cholesterol & $1.48(0.38)$ & $1.24(0.32)$ & $<.01^{*}$ \\
\hline Total cholesterol & $5.89(1.17)$ & $5.32(1.11)$ & $<.01 *$ \\
\hline Hs-CRP & $3.38(6.77)$ & $3.51(7.35)$ & $.37 *$ \\
\hline WH-ratio & $.89(0.07)$ & $.96(0.06)$ & $<.01 *$ \\
\hline
\end{tabular}

* t-test, ** chi square difference test, ***; "About how often during the last 12 month have you been drinking alcohol: A summative indicator in which frequency and total amount of units are equally weighted. "How often do you exercise?", response scale 1-5 (1="never" and 5="about every day"), and "If you exercise as often as once or more per week, how intense do you exercise?" response scale 1-3 ("easy, without breaking into a sweat or losing breath," "losing breath, and breaking into a sweat," or "near exhaustion") were collapsed into a 4point scale where 0 indicates low exercise intensity and 3 indicates high exercise intensity.

items for each category). Missing values were replaced by zero for beer, wine or liquor in cases where the respondents reported the number of glasses consumed for one type of beverage, but left the other beverage items blank. A summative indicator was computed in which frequency and total amount of units were equally weighted. Dummy variables for alcohol of equal sizes were constructed as low, medium and high consumption, based on the distribution in the sample. Exercise intensity was analyzed by two self reported items: "How often do you exercise?" response scale 15 ("never" - "about every day"), and "If you exercise as often as once or more per week, how intensely do you exercise?" response scale 1-3 ("easy, without breaking a sweat or losing breath," "losing breath, and breaking into a sweat," or "near exhaustion"). The two items were combined into a 4-point scale ("low exercise intensity" - "high exercise intensity"). To reduce the number of missing, those reporting no exercise, or exercising less than once a week in the frequency scale were coded as zero on the exercise intensity scale.

\section{Data analysis}

Bivariate correlations among the study variables were calculated. To investigate potential gender-specific patterns of association, regression analyses were conducted for each gender separately. The dependent variable, SMI, was standardized before being used in the analyses. Thus, the b-coefficients show the effect size, and, in the cases where the predictor variables were dichotomised the b-coefficients correspond to Cohen's d.

\section{RESUlts}

For the present sample of $12,255\left(\mathrm{n}_{\mathrm{w}}=6640, \mathrm{n}_{\mathrm{m}}=5610\right)$ participants 65 years or older in HUNT3, men had significantly higher SMI mean scores than women (men: mean=15.4, $\mathrm{SD}=3.1$; women: mean=14.1, $\mathrm{SD}=3.1$ ).

Descriptive statistics for the independent variables included in the present analyses for women and men aged 65 years and older, are presented in Table 1. Men were 0.7 years older and reported significantly more incidents of stroke and heart disease, more smoking and higher alcohol consumption than women. Women had slightly higher mean cholesterol, systolic blood pressure and BMI, but a smaller $\mathrm{WH}$ ratio and lower diastolic blood pressure compared to men.

The results of the bivariate analyses are presented in Table 2, showing relatively moderate correlations between SMI and the study variables. The significant findings of the regression analyses are presented in Table 3. In both genders stroke $\left(b_{\mathrm{w}}=.273, \mathrm{~b}_{\mathrm{m}}=.222\right.$, $\mathrm{p}=0.000)$ and heart disease $\left(\mathrm{b}_{\mathrm{w}}=.112, \mathrm{p}_{\mathrm{w}}=0.004\right.$; $\left.\mathrm{b}_{\mathrm{m}}=.149, \mathrm{p}_{\mathrm{m}}=.000\right)$ were clearly associated with higher levels of SMI, whereas respondents with high SBP reported less SMI than those with moderate SBP $\left(b_{w}=\right.$ -.116, $\left.\mathrm{p}_{\mathrm{w}}=0.008 ; \mathrm{b}_{\mathrm{m}}=-.009, \mathrm{p}_{\mathrm{m}}=.026\right)$. Also in both 
Table 2. Bivariate correlations between variables used in the analyses for the population age 65 years or older $(\mathrm{N}=8950)$.

\begin{tabular}{|c|c|c|c|c|c|c|c|c|c|c|c|c|c|}
\hline & SMI & Gender & Age & $\begin{array}{l}\text { Exer- } \\
\text { cise }\end{array}$ & $\begin{array}{c}\text { Alco- } \\
\text { hol }\end{array}$ & Smoke & $\begin{array}{c}\text { Heart } \\
\text { disease }\end{array}$ & Stroke & BP dia & BP sys & $\begin{array}{l}\text { HDL- } \\
\text { chol }\end{array}$ & Chol & BMI \\
\hline Gender & .13 & & & & & & & & & & & & \\
\hline Age & .08 & $-.02^{\mathrm{ns}}$ & & & & & & & & & & & \\
\hline Exercise & -.05 & .10 & -.23 & & & & & & & & & & \\
\hline Alcohol & $.02^{\mathrm{ns}}$ & .23 & -.19 & -.14 & & & & & & & & & \\
\hline Smoke & .04 & .18 & -.07 & -.07 & .17 & & & & & & & & \\
\hline Heart disease & .10 & .15 & .17 & -.07 & $-.01^{\mathrm{ns}}$ & .06 & & & & & & & \\
\hline Stroke & .07 & .03 & .07 & -.05 & -.03 & .02 & .06 & & & & & & \\
\hline BP diastolic & -.05 & .17 & -.09 & .03 & .06 & $.01^{\mathrm{ns}}$ & -.10 & $-.02^{\mathrm{ns}}$ & & & & & \\
\hline BP systolic & -.08 & $-.02^{\mathrm{ns}}$ & .07 & $-.02^{\mathrm{ns}}$ & $-.02^{\mathrm{ns}}$ & -.05 & -.09 & -.03 & .62 & & & & \\
\hline HDL-cholesterol & -.05 & -.33 & -.05 & .09 & .12 & -.05 & -.18 & -.06 & -.03 & .02 & & & \\
\hline Cholesterol & -.06 & -.25 & -.04 & .00 & $-.01^{\mathrm{ns}}$ & -.05 & -.29 & -.13 & .07 & .09 & .33 & & \\
\hline BMI & -.02 & -.05 & -.08 & -.12 & .06 & -.07 & .04 & $.01^{\mathrm{ns}}$ & .04 & .07 & -.28 & -.09 & \\
\hline WH-ratio & .07 & .44 & .05 & -.10 & .06 & .12 & .12 & .05 & .11 & .03 & -.39 & -.19 & .41 \\
\hline
\end{tabular}

NOTE 1: if not otherwise specified the correlations are significant $(\mathrm{p}<0.05), \mathrm{ns}=$ not significant

Table 3. Association of subjective memory impairment with vascular factors. Summary of significant coefficients from the regression analyses (enter method) conducted separately for women and men. Population age 65 years or older.

\begin{tabular}{llrrrr}
\hline & Predictor & $\mathrm{b}(\mathrm{se})^{\mathrm{a}}$ & \multicolumn{1}{c}{$95 \% \mathrm{CI}$} & \multicolumn{1}{c}{$\beta$} & $\mathrm{p}$ \\
\hline Women $(\mathrm{N}=4635)$ & Age & $.009(.003)$ & $.004-.014$ & .058 & $<.01$ \\
& Exercise intensity & $-.050(.023)$ & $-.095--.005$ & -.034 & .03 \\
& Heart disease $\left(\mathrm{n}_{\text {yes }}=1180\right)$ & $.112(.039)$ & $.035-.188$ & .043 & $<.01$ \\
& ${\text { Stroke }\left(\mathrm{n}_{\text {yes }}=364\right)}^{\text {Men }}$ & $.273(.063)$ & $.148-.397$ & .063 & $<.01$ \\
& Moderate alcohol consumption ${ }^{\mathrm{A}}(\mathrm{n}=1896)$ & $.094(.031)$ & $.033-.154$ & .045 & $<.01$ \\
& High SBP $(\mathrm{n}=479)^{\mathrm{B}}$ & $-.116(.043)$ & $-.201-.031$ & -.045 & $<.01$ \\
& Age & $.014(.003)$ & $.010-.020$ & .086 & $<.01$ \\
& Exercise intensity & $-.062(.021)$ & $-.103--.020$ & -.046 & $<.01$ \\
& Heart disease $(\mathrm{n}=1677)$ & $.149(.034)$ & $.082-.216$ & .068 & $<.01$ \\
& Stroke $(\mathrm{n}=414)$ & $.222(.059)$ & $.105-.338$ & .056 & $<.01$ \\
& Low SBP $(\mathrm{n}=859)^{\mathrm{B}}$ & $.109(.046)$ & $.019-.199$ & .040 & .02 \\
& High SBP $(\mathrm{n}=877)^{\mathrm{B}}$ & $-.009(.047)$ & $-.190--.007$ & -.036 & .03 \\
\hline
\end{tabular}

Note 1: $\mathrm{b}(\mathrm{se})=$ adjusted, un-standardised regression coefficients (standard error), $\beta=$ adjusted, standardised regression coefficient

Note 2: Reference groups: ${ }^{\mathrm{A}}$ low alcohol consumption $(\mathrm{n}=3514),{ }^{\mathrm{B}}$ moderate $\operatorname{SBP}\left(\mathrm{n}_{\text {females }}=4076, \mathrm{n}_{\text {males }}=3849\right)$

Note 3: Variables included in the analysis, but not in the table due to non-significant results: Total cholesterol, HDL-cholesterol, body mass index, Waist-hip ratio, and smoking.

genders, the results indicate that the more intense exercise on a regular basis, the less reported SMI $\left(\mathrm{b}_{\mathrm{w}}=-.050, \mathrm{p}_{\mathrm{w}}=0.030 ; \mathrm{b}_{\mathrm{m}}=-.062, \mathrm{p}_{\mathrm{m}}=.004\right)$. In men, low SBP was associated with significantly more SMI compared to those with moderate SPB $\left(b_{m}=.109\right.$, $\left.\mathrm{p}_{\mathrm{m}}=0.020\right)$. In women, moderate alcohol consumption compared to low alcohol consumption was associated with significantly more SMI $\left(b_{w}=.094, p_{w}=0.003\right)$. The predictor variables included in the investigated model accounted for $1.9 \%$ of the explained variance in women and $3.0 \%$ in men.

\section{DISCUSSION}

This study on subjective memory impairment (SMI) and the association with dementia-related vascular factors included individuals from a large, population- based sample aged 65 years and older. The individuals were assumed to be free from manifest dementia at the time of the data collection because they were able to participate in a comprehensive health survey. In line with results from related studies, stroke $(14,22,23)$ and cardiovascular disease (20) were significantly associated with SMI. Exercise intensity and high systolic blood pressure (SBP) were associated with less SMI.

Taking into account the heterogeneity in the aetiology for the different dementia diseases as well as in SMI $(23,24)$, it is interesting that we found significant relationships between SMI and the investigated vascular factors, even though the associations were mainly moderate or weak. Increased exercise intensity was associated with less SMI in both genders in this study. Whereas the association between exercise and preserved cognition during aging is demonstrated and 
reported in systematic reviews $(25,26)$, the types of physical exercise that may most efficiently contribute to healthy cognitive aging have yet to be validated (26).

That BMI and WH ratio were not associated with SMI in the regression analysis in the present study corresponds with the increasing amount of research reports that being overweight is not associated with cognitive deficits in older people (27). Whereas a recent study found that the prevalence of subjective forgetfulness did not rise with age in a non-demented population (3), our results indicate that SMI increase somewhat with age.

Hypertension, especially very high systolic blood pressure in mid-life, is considered an established risk factor for vascular dementia and a likely risk factor for Alzheimer's disease. In this study in older people, nevertheless, high systolic blood pressure in both women and men was significantly associated with less SMI compared to moderate systolic blood pressure. Also, men with low SBP reported significantly more SMI than men with moderate SBP. Low blood pressure in late life may involve an increased risk of dementia (13) and cognitive deficits $(28,29)$. However; decline in blood pressure in old age may indicate dementia in progress (28). Hence, there is a growing body of evidence showing that the relationship between blood pressure and cognitive functioning varies with age, indicating complex associations which to date are not fully understood.

In our sample, it is likely that some of the respondents with moderate systolic blood pressure were under medical treatment for hypertension at the time of the survey. Among the ten most prescribed drugs in people 70 years or older in Norway are the two antihypertensive drugs metoprolol $(23.1 \%)$ and amlodipine (10.5\%) (30). Numerous studies have evaluated the effect of antihypertensive drugs on cognitive status of hypertensive people, finding mixed results (31). If some of these drugs are harmful, our estimates of the protective effects of high systolic pressure are probably statistically repressed, and being able to adjust for medication might well have given even stronger protective effects.

Cholesterol levels were not significantly related to SMI in this study. The lack of associations between cholesterol levels and SMI is in accord with studies finding that high total serum cholesterol in the middle age, but not in old age, is associated with cognitive impairment in later life (32). Statin use, especially in those with heart disease, has increased extensively the last 10-15 years, which complicates the interpretation of recent research findings of the impact of cholesterol on SMI.

Moderate alcohol consumption may be protective against dementia (33), but in this study, older women with moderate alcohol consumption reported significantly more SMI than women with low alcohol consumption. So far, a specific beneficial level of alcohol intake on cognitive function and dementia has not yet been defined $(33,34)$.

\section{Limitations}

In this study, SMI was measured in a general population, i.e. "healthy" people being able to complete long questionnaires and attend a health examination. This sample is different from people who actively seek help at memory clinics $(7,17,35)$. Because it is likely that individuals not included in this study had more SMI than the participants, it is possible that a nonparticipation bias may have caused an underestimation of the effect estimates.

The fact that SMI is based on self-report, and not on memory testing, put restrictions on the generalizability of our results. Since no formal testing of memory was conducted during the HUNT3 data collection, this study is unable to detect, investigate, or control for potential mismatches between subjectively reported memory problems and results on formal memory tests among the participants. Hence, it is impossible to know if the reported memory complaints in the present population represent normal aging, mild cognitive impairment, minor strokes, or something else. In addition, it is no doubt a number of factors different from memory itself, like questionnaire reporting style in general and expectations to own memory functions, like remembering names of other people, have affected the SMI scores. Still the effects of risk and protective factors demonstrated in our study, like blood pressure and stroke, are much more likely to be associated with memory itself than with factors like reporting style.

\section{Conclusions}

Except for the clear associations between stroke and heart disease and higher levels of SMI, we did not find strong positive relationships between the vascular risk factors and SMI. However, for preventive and treatment purposes, it is notable that exercise intensity and high systolic blood pressure seem to be associated with less SMI in both genders in this large, population-based sample of people aged 65 and older.

\section{ACKNOWLEDGEMENT}

The Nord-Trøndelag Health Study (The HUNT Study) is a collaboration between HUNT Research Centre (Faculty of Medicine, Norwegian University of Science and Technology (NTNU)), Nord-Trøndelag County Council, Central Norway Health Authority, and the Norwegian Institute of Public Health, supported financially by The Research Council of Norway. 


\section{REFERENCES}

1. Iliffe S, Pealing L. Subjective memory problems. BMJ 2010; 340: c1425.

2. Reid LM, MacLullich AMJ. Subjective memory complaints and cognitive impairment in older people. Dement Geriatr Cogn Disord 2006; 22: 471-485.

3. Cooper C, Bebbington P, Lindesay J, Meltzer H, McManus S, Jenkins R, Livingston G. The meaning of reporting forgetfulness: a cross-sectional study of adults in the English 2007 Adult Psychiatric Morbidity Survey. Age Ageing 2011; 40: 711-717.

4. Ausén B, Edman G, Almkvist O, Bogdanovic N. Personality features in subjective cognitive impairment and mild cognitive impairment - early indicators of dementia? Dement Geriatr Cogn Disord 2009; 28: 528-535.

5. Jorm AF, Butterworth P, Anstey KJ, et al. Memory complaints in a community sample aged 60-64 years: associations with cognitive functioning, psychiatric symptoms, medical conditions, APOE genotype, hippocampus and amygdala volumes, and white-matter hyperintensities. Psychol Med 2004; 34: 1495-1506.

6. Dufouil C, Fuhrer R, Alperovitch A. Subjective cognitive complaints and cognitive decline: Consequence or predictor? The epidemiology of vascular aging study. J Am Geriatr Soc 2005; 53: 616-621.

7. Jonker C, Geerlings MI, Schmand B. Are memory complaints predictive for dementia? A review of clinical and population-based studies. Int J Geriatr Psychiatry 2000; 15: 983-991.

8. Barnes LL, Schneider JA, Boyle PA, Bienias JL, Bennett DA. Memory complaints are related to Alzheimer disease pathology in older persons. Neurology 2006; 67: 1581-1586.

9. Wang L, van Belle G, Crane PK, et al. Subjective memory deterioration and future dementia in people aged 65 and older. J Am Geriatr Soc 2004; 52: 2045-2051.

10. Gorelick PB, Scuteri A, Black SE, et al. Vascular contributions to cognitive impairment and dementia. Stroke 2012; 43: 8-10.

11. Flicker L. Cardiovascular risk factors, cerebrovascular disease burden, and healthy brain aging. Clin Geriatr Med 2010; 26: 17-27.

12. Panza F, Capurso C, D'Introno A, et al. Vascular risk factors, alcohol intake, and cognitive decline. $J$ Nutr Health Aging 2008; 12: 376-381.

13. Qiu C, Winblad B, Fratiglioni L. The age-dependent relation of blood pressure to cognitive function and dementia. Lancet Neurol 2005; 4: 487-499.

14. Luck T, Riedel Heller SG, Luppa M, et al. Risk factors for incident mild cognitive impairmentûresults from the German Study on Ageing, Cognition and Dementia in Primary Care Patients (AgeCoDe). Acta Psychiatr Scand 2010; 121: 260-272.

15. Li J, Wang YJ, Zhang M, et al. Vascular risk factors promote conversion from mild cognitive impairment to Alzheimer disease. Neurology 2011; 76: 1485-91.

16. Dickstein DL, Walsh J, Brautigam H, et al. Role of vascular risk factors and vascular dysfunction in Alzheimer's disease. Mt Sinai J Med 2010; 77: 82-102.

17. Panza F, D'Introno A, Colacicco AM, et al. Cognitive frailty: Predementia syndrome and vascular risk factors. Neurobiol Aging 2006; 27: 933-940.

18. Minett TSC, Dean JL, Firbank M, English P, O'Brien JT. Subjective memory complaints, white-matter lesions, depressive symptoms, and cognition in elderly patients. Am J Geriatr Psychiatry 2005; 13: 665-671.

19. Nilsson K, Gustafson L, Hultberg B. Plasma homocysteine is elevated in elderly patients with memory complaints and vascular disease. Dement Geriatr Cogn Disord 2007; 23: 321-326.

20. Haley AP, Hoth KF, Gunstad J, et al. Subjective cognitive complaints relate to white matter hyperintensities and future cognitive decline in patients with cardiovascular disease. Am J Geriatr Psychiatry 2009; 17: 976985.

21. Fromholt P, Berg S. Self-reported memory and cognitive performance among 75 -year old people from three Nordic cities. In: Heikkinen E, Berg S, Schroll M, Steen B, Viidik A (Eds.), Functional Status, Health and Aging, The NORA Study (Series: Facts, Research and Intervention). Paris: Serdi Publishing Company 1997: 55-65.

22. Stewart R, Russ C, Richards M, et al. Depression, APOE genotype and subjective memory impairment: a cross-sectional study in an African-Caribbean population. Psychol Med 2001; 31: 431-440.

23. Peltz CB, Corrada MM, Berlau DJ, Kawas CH. Cognitive impairment in nondemented oldest-old: Prevalence and relationship to cardiovascular risk factors. Alzheimer's and Dementia 2012; 8 (2): 87-94.

24. Paradise M, Glozier N, Naismith S, Davenport T, Hickie I. Subjective memory complaints, vascular risk factors and psychological distress in the middle-aged: a cross-sectional study. BMC Psychiatry 2011; 11: 108.

25. Ahlskog JE, Geda YE, Graff-Radford NR, Petersen RC. Physical exercise as a preventive or diseasemodifying treatment of dementia and brain aging. Mayo Clin Proc 2011; 86: 876-884 .

26 Miller DI, Taler V, Davidson PSR, Messier C. Measuring the impact of exercise on cognitive aging: methodological issues. Neurobiol Aging 2011; 33 (3): 622.e29-622.e43. 
27. Smith E, Hay P, Campbell L, Trollor JN. A review of the association between obesity and cognitive function across the lifespan: Implications for novel approaches to prevention and treatment. Obes Rev 2011; 12: 740755.

28. van Vliet P, Westendorp RGJ, van Heemst D, de Craen AJM, Oleksik AM. Cognitive decline precedes latelife longitudinal changes in vascular risk factors. J Neurol Neurosurg Psychiatry 2010; 81: 1028.

29. Hestad K, Kveberg B, Engedal K. Low blood pressure is a better predictor of cognitive deficits than the apolipoprotein e4 allele in the oldest old. Acta Neurol Scand 2005; 111: 323-328.

30. Rønning M, Berg C, Litleskare I, Mahic M, Sakshaug S, Selmer R, Strøm H. Legemiddelstatistikk 2009:2 Reseptregisteret 2004-2008. Oslo: Norwegian Institute of Publich Health, 2009. ISBN: 978-82-8082-198-0.

31. Cherubini A, Lowenthal DT, Paran E, Mecocci P, Williams LS, Senin U. Hypertension and cognitive function in the elderly. Disease-a-Month 2010; 56: 106-147.

32. van Vliet P, van de Water W, de Craen AJM, Westendorp RGJ. The influence of age on the association between cholesterol and cognitive function. Exp Gerontol 2009; 44: 112-122.

33. Panza F, Capurso C, D'Introno A, et al. Alcohol drinking, cognitive functions in older age, predementia, and dementia syndromes. J Alzheimer's Dis 2009; 17: 7-31.

34. Peters R, Peters J, Warner J, Beckett N, Bulpitt C. Alcohol, dementia and cognitive decline in the elderly: a systematic review. Age Ageing 2008; 37 (5): 505-512.

35. Mitchell AJ: The clinical significance of subjective memory complaints in the diagnosis of mild cognitive impairment and dementia: a meta-analysis. Int J Geriatr Psychiatry 2008; 23 (11): 1191-1202. 